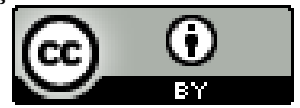

\title{
DOS (DES) ENCONTROS ENTRE PSICOLOGIA, POLÍTICAS PÚBLICAS E COMUNIDADES QUILOMBOLAS: REFLEXÕES A
} PARTIR DE UMA REVISÃO DE LITERATURA

\author{
Maria Gisele Alexandre da Silva ${ }^{1}$ \\ Centro Universitário Central Paulista (UNICEP), Instituto de Psicologia, São \\ Carlos, SP, Brasil.
}

\begin{abstract}
Dra. Elisabete Figueroa dos Santos ${ }^{2}$
Centro Universitário Central Paulista (UNICEP), Curso de Graduação em, São Carlos, SP, Brasil.; Universidade Federal da Bahia (UFBA), Instituto de Psicologia, Salvador, BA, Brasil.
\end{abstract}

Resumo: O presente artigo teve como objetivo identificar e caracterizar estudos a respeito da inserção da Psicologia dentro das comunidades quilombolas, com ênfase no trabalho voltado às políticas públicas e à saúde mental nos quilombos do Brasil. Para tanto, realizou-se uma revisão de literatura a partir de uma abordagem qualitativa. Os artigos foram pesquisados em três bancos de dados: PePSIC- BVS, SciELO e Google Scholar. $\mathrm{Na}$ busca, foram utilizados os descritores: "Políticas públicas", "saúde mental quilombola", "psicologia", "quilombo", "Brasil" e "saúde". Constatou-se que existem poucos estudos voltados à produção de conhecimento nessa área, tanto relacionados ao trabalho da Psicologia, quanto às políticas públicas de saúde mental direcionadas à população quilombola. Verificou-se haver um distanciamento do trabalho da Psicologia com relação às comunidades quilombolas. Isso aponta para a necessidade de capacitação de psicólogos para atuar nesses locais, tendo em vista suas especificidades sociais e culturais. Nesse sentido, a Psicologia pode e deve assumir o compromisso social de contribuir para o desenvolvimento de políticas públicas de saúde e saúde mental nessas comunidades, criando estratégias que diminuam o impacto do racismo e das desigualdades étnico-raciais.

Palavras-chave: Políticas públicas; Psicologia; Saúde mental quilombola; Brasil.

\footnotetext{
${ }^{1}$ Graduação em Psicologia pelo Centro Universitário Central Paulista. E-mail: giselealexandre.psi@hotmail.com ; ORCID: https://orcid.org/0000-0001-8688-4203

2 Doutora em Psicologia pela Universidade Federal de São Carlos (UFSCar); docente do Centro Universitário Central Paulista (UNICEP) e docente substituta do Instituto de Psicologia da Universidade Federal da Bahia (UFBA). E-mail: bete.figueroa@gmail.com ; ORCID: https://orcid.org/0000-00032017-8845
} 


\section{LITERATURE REVIEW}

Abstract: This article aimed to identify and characterize studies on the insertion of Psychology within quilombola communities, with an emphasis on work aimed at public policies and mental health in quilombos in Brazil. Therefore, a literature review was carried out using a qualitative approach. The articles were searched in three databases: PePSIC-BVS, SciELO and Google Scholar. In the search, the following descriptors were used: "Public policies", "quilombola mental health", "psychology", "quilombo", "Brazil" and "health". It was found that there are few studies aimed at the production of knowledge in this area, both related to the work of Psychology and public policies on mental health aimed at the quilombola population. It was verified that there is a distancing of the work of Psychology in relation to the quilombola communities. This points to the need for training psychologists to work in these places, considering their social and cultural specificities. In this sense, Psychology can and should assume the social commitment to contribute to the development of public health and mental health policies in these communities, creating strategies that reduce the impact of racism and ethnic-racial inequalities.

Keywords: Public policies; Psychology; Quilombola mental health; Brazil.

\section{SOBRE LOS (DES) ENCUENTROS ENTRE PSICOLOGÍA, POLÍTICAS PÚBLICAS Y COMUNIDADES QUILOMBOLAS: REFLEXIONES DE UNA REVISIÓN DE LA LITERATURA}

Resumen: Este artículo tuvo como objetivo identificar y caracterizar estudios sobre la inserción de la Psicología en las comunidades quilombolas, con énfasis en el trabajo orientado a las políticas públicas y la salud mental en quilombos en Brasil. Por lo tanto, se realizó una revisión de la literatura con un enfoque cualitativo. Los artículos se buscaron en tres bases de datos: PePSIC-BVS, SciELO y Google Scholar. En la búsqueda se utilizaron los siguientes descriptores: "Políticas públicas", "salud mental quilombola", "psicología", "quilombo", "Brasil" y "salud". Se encontró que existen pocos estudios dirigidos a la producción de conocimiento en esta área, tanto relacionados con el trabajo de la Psicología como con las políticas públicas en salud mental dirigidas a la población quilombola. Se constató que existe un distanciamiento del trabajo de la Psicología en relación a las comunidades quilombolas. Esto apunta a la necesidad de formar psicólogos para trabajar en estos lugares, considerando sus especificidades sociales y culturales. En este sentido, la Psicología puede y debe asumir el compromiso social de contribuir al desarrollo de políticas de salud pública y salud mental en estas comunidades, creando estrategias que reduzcan el impacto del racismo y las desigualdades étnico-raciales.

Keywords: Políticas públicas; Psicología; Salud mental quilombola; Brasil.

Palabras clave: Políticas públicas; Psicología; salud mental quilombola; Brasil.

SUR LES (DE)RENCONTRES ENTRE PSYCHOLOGIE, POLITIQUES PUBLIQUES ET COMMUNAUTES QUILOMBOLAS : REFLEXIONS A PARTIR D'UNE REVUE DE LA LITTERATURE 
Résumé: Résumé : Cet article visait à identifier et caractériser les études sur l'insertion de la psychologie au sein des communautés quilombolas, en mettant l'accent sur les travaux visant les politiques publiques et la santé mentale dans les quilombos au Brésil. Une revue de la littérature a donc été réalisée selon une approche qualitative. Les articles ont été recherchés dans trois bases de données : PePSIC-BVS, SciELO et Google Scholar. Dans la recherche, les descripteurs suivants ont été utilisés : "Politiques publiques », « quilombola santé mentale », « psychologie », « quilombo », « Brésil » et « santé ». Il a été constaté qu'il existe peu d'études visant à la production de connaissances dans ce domaine, à la fois liées aux travaux de la psychologie et aux politiques publiques de santé mentale visant la population quilombola. Il a été vérifié qu'il y a une distanciation du travail de la Psychologie par rapport aux communautés quilombolas. Cela souligne la nécessité de former des psychologues pour travailler dans ces lieux, compte tenu de leurs spécificités sociales et culturelles. En ce sens, la psychologie peut et doit assumer l'engagement social de contribuer au développement de politiques de santé publique et de santé mentale dans ces communautés, en créant des stratégies qui réduisent l'impact du racisme et des inégalités ethnico-raciales.

Mots-clés : Politiques publiques ; Psychologie; santé mentale des Quilombolas ; Brésil.

\section{INTRODUÇÃO}

Os negros estão presentes desde o início da formação social brasileira, uma vez que o Brasil nasceu apoiado na escravização ameríndia e negro-africana. Contudo, devese demarcar que a história das civilizações africanas é anterior, mais vasta e rica que aquela circunscrita à sua trajetória colonial. Assim, compreende-se que a história do negro

tem seu início em África, lugar em que o negro vivia em terras de várias e diferentes etnias, com diversidade étnico-cultural e religiões distintas, com práticas e tecnologias também diversas - diversidades essas trazidas ao Brasil através dos africanos que para cá foram trazidos.

Isto posto, ressalta-se que as práticas, organizações e complexidades das várias sociedades africanas ao longo dos séculos é algo irredutível à leitura e problematização do tráfico escravista às Américas. No entanto, compreender os processos envolvidos na chegada e permanência dos africanos neste território é essencial para se entender elementos importantes que compõem a cultura brasileira.

A chegada do negro no Brasil escravagista foi marcada pelo sequestro de homens e mulheres negros/as trazidos da África que, compulsoriamente, foram arrancados do seu continente para trabalhar nas colônias agrícolas da América portuguesa, sob o regime de escravidão (SCHWARCZ; STARLING, 2015). 
Entre os séculos XV e XVI, o Brasil se tornou o principal destino de africanos escravizados do mundo. O transporte dos escravizados para o Brasil ocorreu através dos navios negreiros, em condições totalmente desumanas. Depois de passar vários dias enfrentando uma viagem terrível, os africanos que não morriam na travessia aportavam em terras tupiniquins e eram distribuídos em portos para serem vendidos como mercadoria. A mão de obra compulsória que antes era realizada apenas por indígenas passou a ser progressivamente substituída por negros escravizados. Suas atividades principais foram desenvolvidas, primeiramente, nos engenhos e outras culturas da região nordeste da colônia, inclusive em ofícios que demandavam especialidade. Com o decorrer dos séculos, e também durante praticamente todo o período Imperial, a mão de obra escrava negra foi adotada em todo território brasileiro, sendo utilizada em grande escala também na extração do ouro e, depois, na cultura cafeeira no centro-sul do país, contribuindo assim, para a construção do Brasil (MARQUESE, 2006).

Desse modo, por mais que a elite brasileira, embasada no sistema social colonialista, insista em colocar o negro como inferior e não dê a ele o devido reconhecimento por toda sua contribuição, é de suma importância que a história do negro no brasil não se resuma apenas à sua objetificação, mesmo com o esforço da elite brasileira, para impedir o negro de viver suas raízes étnico-culturais, excluindo-os da divisão de riquezas, é importante pontuar que os africanos escravizados participaram da construção e desenvolvimento do Brasil. E com sua riqueza étnico-cultural, contribuíram para tradições e costumes, introduzidos na culinária, musica, religião, idioma, dança, técnicas etc.

\section{RESISTENCIA E ENFRENTAMENTO}

O povo negro desde que foi retirado do seu continente vivencia uma história de luta e resistência. Dessa forma, cabe considerarmos os movimentos de enfrentamento às práticas opressivas escravocratas. Um dos mais importantes marcos de resistência à coisificação e exploração impostas pela escravização foi a quilombagem. Que de acordo com Moura (1992), foi um movimento de rebeldia organizado e dirigido pelos escravos que se espalhou por todo território nacional, influenciando de forma poderosa para o fim do trabalho escravo. As manifestações de processos raciais e sociais também estão 
incluídas no conceito de quilombagem, dois exemplos são: as insurreições baianas do século XIX, e o bandoleirismo dos escravos fugidos, sendo ambos movimentos emancipacionistas que se uniram a pauta quilombola e passaram a sair em grupos ou separadamente, atacando povoados e estradas como forma de reivindicação dos direitos quilombolas.

O termo quilombo no Brasil, teve origem com o intuito de destacar um espaço e um movimento de resistência ao sistema escravocrata, formado por negros e negras que fugiram e formaram núcleos de poder, produção e organização social. Nesses núcleos foram incorporados brancos desertores e índios. A criação do quilombo foi a expressão mais radical de ruptura com o sistema brasileiro latifundiário e escravista. Não há dúvidas que o quilombo é desde seu início a unidade básica de resistência escrava, independente do seu tamanho ou organização. Com o quilombismo Nascimento (2019) propõe uma nova forma de organização social. Com uma perspectiva anti-imperialista e panafricanista, tem o intuito de unir os negros, com a visão de que os negros são a maior parte da população brasileira, e desse modo, cabe aos negros dirigir o brasil lutar contra a exploração, opressão, racismo e desigualdades motivadas por raça cor religião ou ideologia.

De acordo com Silva (2012,), atualmente, a palavra "Quilombo" designa toda comunidade rural que contém agrupamento de descendentes de escravos que vivem da cultura de subsistência. Porém, cabe indicar que a origem dos quilombos se deu a partir da resistência dos africanos ao escravismo colonial, porém sua formação como núcleo quilombola teve início apenas no contexto da invasão Holandesa a Pernambuco no século XVII, quando uma grande quantidade de negros escravizados aproveitou a desordem militar e fugiu, formando um núcleo de resistência, de modo a criar uma fronteira social, cultural e militar contra os opressores (MARQUESE, 2006).

Os quilombos não recebiam apenas negros fugitivos, além dos negros, eram acolhidos curibocas, índios e diversas pessoas que estavam sendo perseguidas pelo sistema colonial. Desde o início da escravidão o quilombismo abrange todo o território nacional. Alguns dos primeiros quilombos brasileiros são: o quilombo do Rio Vermelho; quilombo São Benedito do Céu; quilombo do Ambrósio; quilombo do Motuca e o quilombo de Palmares, que é conhecido como maior movimento de resistência da população africana escravizada no Brasil. Estima-se que esse refúgio quilombola recebeu 
entre seis e trinta mil escravizados fugitivos e, assim, tornou-se o maior quilombo da história da América Portuguesa (MOURA, 1993).

O Brasil foi o último país independente do ocidente a abolir a escravidão. A libertação oficial só ocorreu com promulgação da Lei Áurea em 13 de maio de 1888, como resultado das variadas formas de resistência e luta dos negros, do movimento abolicionista e das pressões estrangeiras. Entretanto, isso não significou a transformação dos negros, agora libertos, efetivamente em cidadãos. Sem nenhum tipo de indenização, jogados à própria sorte, sofrendo variados tipos de preconceitos, discriminação e segregação, negros e negras permaneceram excluídos da sociedade (FURTADO; PEDROZA; ALVES, 2014).

Após a abolição, o negro continuou ocupando uma posição de inferioridade em relação à população branca, que manteve seus privilégios, com condições muito melhores para construir sua subjetivamente de forma afirmativa, enquanto a população negra tinha que lutar por reconhecimento, contra estereótipos negativos e o sentimento e a situação de inferioridade, num país que manteve sua cultura racista inalterada, reproduzindo a desigualdade racial. Nesse contexto, historicamente, o negro sempre conviveu com a desqualificação também de seus lugares, espaços e ocupações estando atualmente ocupando o topo da lista dos índices de violência e pobreza do Brasil (FERREIRA; CAMARGO, 2011).

Nesse sentido, Vieira e Monteiro (2013) ressaltam que olhar as questões quilombolas no Brasil é deparar-se com um povo marcado por dilemas e conflitos. Entre os vários problemas, destacam-se a pobreza extrema; interferência na cultura; dificuldade de acesso à saúde, segurança e à educação; conflitos institucionais; invisibilidade e a discriminação racial. Em vista disso, evidencia-se os embates rumo à redefinição da identidade desse povo diante da sua luta como agente de suas próprias vidas, com direito à dignidade, cidadania e saúde.

A transformação do corpo negro como escravo vem do colonialismo e foi arquitetada tendo-se em vista produzir riquezas via capital para os proprietários brancos por meio de repressão e opressão estabelecidas pelo estado (MOORE, 2007). Dessa forma se construiu, discriminação, racismo e preconceito voltado aos corpos negros. Esses três fenômenos têm múltiplas, produções sociais que atingem a população como 
um todo, seu efeito cria barreiras que vão contra o desenvolvimento de indivíduos e grupos historicamente vitimados (NASCIMENTO, 2002).

Nesse sentido, Vieira; Monteiro (2013), ressaltam que olhar as questões quilombolas no Brasil é se deparar com um povo marcado por dilemas e conflitos. Entre os vários problemas, destacam-se a pobreza extrema; interferência na cultura; dificuldade de acesso à saúde, segurança e à educação; conflitos institucionais; invisibilidade e a discriminação racial vivenciada por essa população. Em vista disso, evidencia-se a redefinição da identidade desse povo diante da sua luta como agente de suas próprias vidas, com direito à dignidade, cidadania e saúde.

Nesse contexto, o trabalho da Psicologia é muito importante na luta para romper essas barreiras. Como uma ciência da subjetividade e com diversas dimensões para explicar alguns fenômenos - entre eles: apatia social, o efeito psíquico do racismo, preconceito e discriminação nas relações humanas -, a partir de sua inserção neste contexto de atuação, pode também auxiliar na construção e desenvolvimento de políticas públicas voltadas à população remanescente de quilombo (MÄDER, 2016). Dessa maneira, é importante considerar o conceito de saúde, e atentar-se à saúde mental de forma ampla, refletir a respeito de uma combinação entre o impacto social, econômico, político e cultural da sociedade, na vivência de cada indivíduo e de grupos.

Dessa forma, esta temática torna-se relevante, uma vez que evidencia a necessidade de reflexões a respeito da luta do negro no Brasil, da formação dos quilombos e da (não) atuação da Psicologia junto às políticas públicas voltadas à saúde mental da população quilombola. Objetiva-se, assim, chamar a atenção para essa dívida da Psicologia e também para a necessidade de se construir estratégias para o trabalho da (o) psicóloga (o) junto às políticas públicas voltadas às comunidades quilombolas.

Desse modo, esse artigo tem como questão central de pesquisa verificar como vem sendo a inserção da Psicologia dentro das comunidades quilombolas e como deve ser a atuação dos (das) psicólogos(as) no âmbito das políticas públicas em comunidades quilombolas no Brasil, sua proposta é investigar e caracterizar estudos a respeito da inserção da (o) psicóloga (o) dentro das comunidades quilombolas, com ênfase nas políticas públicas e de saúde mental no contexto dos quilombos do Brasil.

Cabe ponderar que o interesse por este assunto se deu, primeiramente, por ser uma das autoras estudante de Psicologia e remanescente de quilombo e em razão de se 
constatar uma grande escassez de estudos na área da Psicologia sobre as comunidades quilombolas, sobretudo no que diz respeito à atuação de psicólogas (os) junto a essa população. Portanto, espera-se que este trabalho contribua para colocar em debate as demandas das comunidades quilombolas para a atuação da Psicologia, assim como à histórica reticência dessa importante área do conhecimento em estudar e atuar junto a essas comunidades.

\section{METODOLOGIA}

O presente trabalho foi desenvolvido através de uma revisão sistemática de caráter descritivo, com abordagem qualitativa. O método de revisão sistemática utilizou a literatura sobre o tema como fonte, disponibilizando um resumo das evidências relacionadas a uma estratégia de intervenção científica, por meio de sistema de busca, aplicação de métodos, síntese da informação selecionada e apreciação crítica (SAMPAIO; MANCINI, 2007).

A partir da perspectiva sistemática qualitativa, buscou-se assegurar a validade descritiva, interpretativa e teórica. As abordagens qualitativas das revisões sistemáticas permitem ao pesquisador entender ou interpretar questões sociais, emocionais, culturais, comportamentos, interações e vivências que acontecem no âmbito do cuidado em saúde ou na sociedade, a partir da ocorrência de um fenômeno, além de subsidiar a proposição de novas teorias. Os procedimentos de validade de uma revisão sistemática geram resultados úteis para a prática. A validade descritiva refere-se à identificação de estudos relevantes por meio de todos os meios acessíveis de busca (DE-LA-TORRE-UGARTEGUANILO; TAKAHASHI; BERTOLOZZI, 2011).

Conforme indicam Felicíssimo et al. (2013), investigar a produção científica de uma área acerca de determinado tema contribui para a construção de uma reflexão atualizada sobre ele, capaz de nortear a prática profissional dessa área, ao favorecer o intercâmbio de ideias, procedimentos e resultados de pesquisas.

Seguindo o método de revisão sistemática da literatura, cumpriu-se os seguintes passos:

A elaboração da pergunta de pesquisa é a primeira etapa de um trabalho de revisão. Nossa pergunta foi: “O trabalho do psicólogo no âmbito das políticas públicas, encontra-se inserido dentro das comunidades quilombolas?" 
A busca na literatura. A pesquisa foi feita através de buscas de literatura científica nas seguintes bases de dados: PePSIC, BVS-Psi, SciELO e Google Scholar. Na busca, foram utilizados os filtros "Brasil", "português", "período entre 2011 a 2020" e as palavras-chave "Políticas públicas", "saúde mental", "psicologia", "quilombo" e "saúde". Os descritores utilizados foram: "Políticas públicas", "saúde mental quilombola", "saúde mental", "psicologia", "quilombo" e "saúde". Na construção dos descritores, foram realizadas algumas combinações até encontrar as que apresentavam uma quantidade significativa de artigos a respeito do tema, depois de realizar alguns testes, os padrões de busca utilizados foram: "quilombos AND Psicologia OR Brasil; quilombo OR políticas públicas AND psicologia; quilombo AND saúde; quilombo OR saúde mental AND psicologia. Através da leitura dos resumos, foram identificados 16 artigos no SciELO e PePSIC-BVS e 12 no Google Scholar, totalizando-se 28 artigos.

No processo de extração dos dados, os estudos selecionados foram lidos na íntegra, realizando-se a análise de conteúdo e a exposição de forma descritiva, categorizando seu delineamento, procedimentos de intervenção, resultados obtidos e limitações; visando observar, contar, descrever e classificar os dados, com o intuito de reunir o conhecimento produzido sobre o tema explorado na revisão.

$\mathrm{Na}$ avaliação dos estudos selecionados, para extração das informações mencionadas foram sistematizados os seguintes dados: Numeração, autor(es), título, periódico, local de estudo, ano do artigo, volume, número, descritores/palavras-chave, objetivo/questão de investigação e metodologia, principais resultados e discussões, entre outros.

A organização da análise dos dados foi elaborada por meio de um quadro contendo as seguintes categorias: Políticas públicas de saúde mental nas comunidades quilombolas; demandas de políticas públicas de saúde direcionadas às comunidades quilombolas; atuação dos psicólogos nas políticas públicas de saúde mental das comunidades quilombolas; possibilidades de atuação e estratégias do trabalho em Psicologia junto às comunidades quilombolas. Posteriormente, os dados mais salientes e pertinentes foram extraídos e relatados.

A apresentação dos resultados foi feita de acordo com os seguintes tópicos a partir das organizações prévias mencionadas, optando-se pelo formato de exposição, problematização e discussão de cada uma das categorias extraídas. Dessa forma, a seção 
dos resultados é composta pelas seguintes subseções: políticas públicas direcionadas à saúde e saúde mental da população quilombola; a (não) inserção da Psicologia no contexto das comunidades quilombolas.

\section{POLÍTICAS PÚBLICAS DIRECIONADAS À SAÚDE E SAÚDE MENTAL DA POPULAÇÃO QUILOMBOLA}

As comunidades quilombolas foram reconhecidas e tiveram seus direitos oficializados pelo Estado Brasileiro em 1988, por meio do artigo 68 do Ato das Disposições Constitucionais Transitórias da Constituição (ADCT), que afirmou seus direitos territoriais (FERNANDES; MUNHOZ, 2012); (TEIXEIRA; SAMPAIO, 2019). Desde a década de 1970 os movimentos negros lutam na ressignificação da visão do quilombo, e busca de direitos quilombolas, e nesse processo de luta e resistência os movimentos quilombolas conseguiram, eleger o 20 de outubro como data da consciência negra, sendo essa data escolhida, por marcar a data de assassinato de Zumbi dos palmares, o herói do quilombo palmarino.

Gomes; Madeira; Brandão (2020); Cardoso e Gomes (2018), salientam que o movimento negro é visto como ator histórico das mudanças no cenário de políticas públicas relacionadas à população negra, assim como o responsável pela abertura dos espaços promotores do necessário debate sobre a questão racial no país. A partir de suas ações, reivindicações e preocupação com o racismo e com as relações étnico-raciais na sociedade brasileira, o movimento negro provocou mudanças históricas importantes. Conseguiu ressignificar o conceito de quilombo e trazer à tona a discussão sobre a identidade negra, atribuindo a ambos valores positivos e mostrando a resistência do povo negro contra o sistema de injustiças. Como resultado, os quilombos, antes vistos como espaços de população marginalizada, passaram então a serem vistos como lugar de luta política por território, identidade e cidadania.

Os movimentos negros, com o decorrer dos séculos, foram se atualizando, o que contribuiu também para a compreensão de que o quilombo não se restringe apenas à parte rural, existem também os quilombos urbanos. Algumas das ideias que levaram ao pensamento e às ações dos movimentos negros a respeito do quilombo, foram: passou-se a ver a população negra como majoritária; notou-se o protagonismo negro na organização 
da história nacional; contatou-se a influência do racismo anti-negro como fator que interfere diretamente na produção econômica, cultural, política, social da população negra; e a mudança na compreensão da cultura negra e do socialismo, em que se passa a pensar uma forma de organização com base nos valores culturais africanos, com valorização da cultura e a validação de valores coletivos e comunitários (CUNHA JUNIOR, 2012).

As políticas públicas direcionadas à população quilombola começaram a ser aplicadas no Brasil a partir dos anos 2000, por meio da Política Nacional de promoção da Igualdade Racial (PNPIR), do Programa Brasil Quilombola e da criação da Secretaria Especial de Políticas e Promoção para a Igualdade Racial (SEPPIR). Porém, mesmo depois da criação dessas políticas essa população se depara com vários empecilhos para a efetivação dos seus direitos, o que contribui para a manutenção da dificuldade no acesso à cidadania e na diminuição das desigualdades (SILVA, 2018).

Segundo o Ministério da Saúde (2018), as condições precárias de vida enfrentadas pela população negra e o racismo contribuem para que o número de vítimas de suicídios seja maior no grupo de homens negros. Entre 2012 e 2016, o número de negros vítimas de suicídio passou de 53,3\% para 55,4\% (BRASIL, 2018).

Sendo assim, não dá para falar de políticas públicas e saúde mental da população quilombola sem ressaltar o papel social histórico do racismo estrutural e institucional.

Conforme ressalta Almeida:

[...] o racismo institucional é uma forma sistemática de discriminação que tem sua base direcionada à raça, e ocorre em diversos órgãos, sendo eles governamentais ou institucionais. Transcende o âmbito da ação individual, ao frisar a dimensão do poder como elemento constitutivo das relações raciais, não somente o poder de um indivíduo de uma raça sobre outro, mas de um grupo sobre outro, algo possível quando há o controle direto ou indireto de determinados grupos sobre o aparato institucional (ALMEIDA, 2019, p. 31).

Nesse sentido, Almeida nos diz:

As instituições são racistas porque a sociedade é racista! O racismo está vinculado com a estrutura social, atrelado ao modo como se controla as relações políticas, econômicas, familiares e jurídicas, sendo assim, ele não pode ser colocado como uma patologia, muito menos um desarranjo cultural, pois o racismo é estrutural e faz parte do processo social de uma sociedade em que o racismo está presente como regra e não exceção (ALMEIDA, 2019, p. 33). 
De acordo com a Cartilha Relações Raciais: referencias técnicas para a atuação do psicólogo do CRP - Conselho Regional de Psicologia de Brasília (2017), o racismo é uma ideologia complexa, sistêmica e violenta, que está inserido em diversos âmbitos, sendo eles: cultural, político, institucional, econômico, ético, social etc. Encontra-se inserido na vida subjetiva do indivíduo, edificando a ideia de que existem raças superiores e inferiores, e isso acaba influenciando de forma negativa no acesso da população negra a serviços sociais fundamentais.

A política de inclusão da população quilombola no Ministério da Saúde teve início em 2004 com a Portaria n..$^{\circ} 1.434$, de 14/07/2004, que proporcionou um incentivo para a ampliação de equipes de estratégia da saúde para as comunidades quilombolas (FREITAS et al., 2011).

O Programa Brasil Quilombo (PBQ), criado em 2004, com o objetivo de garantir o acesso à terra, à saúde e à educação, como medida de preservação e promoção das manifestações culturais dessas comunidades, se constitui em outra iniciativa vista como importante marco das políticas públicas direcionadas às comunidades quilombolas. Sua institucionalização pela Agência Social Quilombola, através do Decreto n. 6.261 (2007), definiu as comunidades quilombolas como grupos com características étnicas e raciais autoatribuídas, que possuem trajetória histórica própria, relações territoriais específicas e presunção de ancestralidade negra relacionada com a escravidão (CUNHA; ALBANO, 2017); (GOMES; MADEIRA; BRANDÃO, 2020). Esse decreto também definiu quatro eixos destinados à população quilombola, dentre os quais se encontra o incentivo a iniciativas de produção de direitos das comunidades quilombolas junto a diferentes órgãos do governo, com o objetivo de se promover o acesso às comunidades, água potável, energia elétrica e saúde (TEIXEIRA E SAMPAIO, 2019). Os autores citam a importância das lutas por direitos promovidas pelo Movimento Negro e a criação do Programa Brasil Quilombo como marcos históricos de avanços nas políticas públicas de saúde direcionadas à população quilombola, visto que ambos foram fundamentais para a melhoria do acesso dessa população às políticas públicas de saúde.

Porém, é ressaltado por Batista e Rocha (2020) que existem poucos artigos e políticas públicas focados na saúde dessa população. Conforme Roso et al. (2011) e Costa e Scarcelli (2016), estudos em comunidades quilombolas de várias regiões do Brasil têm apontado para a necessidade de efetivação de ações de políticas públicas que contemplem 
a população negra, e que as políticas públicas voltadas às comunidades remanescentes de quilombos estão em sua maioria direcionadas à luta por terras. Porém, essas políticas não respondem inteiramente às demandas dessa população, que além da necessidade de luta por terra, apresenta outras carências, sendo estas relacionadas às dificuldades de acesso a programas sociais, falta de conhecimento sobre políticas de assistência social, discriminação e privação dos direitos humanos e de cidadania, entre outras. As necessidades vão muito além do necessário e justo direito a terra, visto que são muitas as carências sociais, sendo uma delas os serviços de saúde, que ainda são bastante precários e deficientes.

Teixeira e Sampaio (2019) e Gomes; Madeira; Brandão (2020), observam um alto grau de distância institucional entre os executivos estaduais e municipais e as comunidades quilombolas, evidenciado na ausência de políticas públicas com recorte racial advinda do racismo institucional. Dentro dessa perspectiva, os autores mencionam que não adotar um recorte racial na produção programática institucional, não priorizar e implementar dispositivos e estratégias de redução das disparidades e promoção da equidade ao acesso dos negros a benefícios gerados pelo Estado configura-se como indicativo de racismo institucional. Gomes ressalta que "Raça é um elemento estruturante de como os direitos foram e são concebidos, negados e usufruídos de forma desigual no Brasil e em todo o mundo" (GOMES; MADEIRA; BRANDÃO, 2020).

O racismo institucional, de acordo com Silva e Chaves (2015), é uma das problemáticas históricas enfrentadas pelas comunidades tradicionais, pois assim as desigualdades são mantidas, os direitos, mesmo garantidos constitucionalmente, não se efetivam.

Rocha e Santos (2015) pontuam que a Política Nacional de Saúde Integral da População Negra - PNSIPN (2007) e o Estatuto da Igualdade Racial (2010) são documentos referenciais para a política de saúde pública da população negra. São exemplos da importância dos movimentos sociais na luta pela superação das iniquidades enfrentadas por essa população. Assim, também, a Política Nacional de Assistência Social - PNAS, aprovada em 2004, é citada como base para a criação de serviços estruturados no Sistema Único de Assistência Social - SUAS, voltado para a criação de serviços para a população em situação de risco e vulnerabilidade social, através de instituições como 
os Centros de Referência da Assistência Social - CRAS, que tem o trabalho voltado para os territórios com alto índice de vulnerabilidade e risco social (SILVA; CHAVES, 2015).

Desse modo, a PNSIPN é uma política que tem o intuito de desvelar e retirar as condições sociais vivenciadas pelo povo negro do anonimato. A PNSIPN abrange a saúde da população negra de forma ampliada e busca contemplar as especificidades das comunidades quilombolas. A PNSIPN afirma o reconhecimento do racismo institucional e/ou estrutural e das desigualdades étnico-raciais como determinantes sociais das condições de saúde. Antes da PNSIPN, foi aprovada a Portaria n 1.434 do Ministério da Saúde. A partir deste documento, iniciou-se a instalação de Unidades Básicas de Saúde (UBS) em comunidades quilombolas, com o intuito de ampliar o acesso à saúde dessa população. Tanto a PNSIPN, quanto a Portaria 1.434, atuam como marco regulatório que buscam garantir o direito à saúde a grupos historicamente marginalizados. (FERNANDO; SANTOS, 2019); (BATISTA; ROCHA, 2020).

Conforme colocado tanto por Rocha e Santos (2015), como por Teixeira e Sampaio (2019), a Secretaria Especial de Promoção da Igualdade Racial (SEPIR) surgiu com o objetivo de implementar a Política de Promoção da Igualdade Racial, e com a função de articular as várias políticas públicas dispersas nos diferentes ministérios, fundações e secretarias, inclusive as políticas de saúde relacionadas à população quilombola.

Segundo Gomes; Madeira; Brandão (2020), de acordo com os dados atualizados da Fundação Cultural Palmares (2019), existem 3.386 comunidades quilombolas, sendo 2.744 certificadas. A maior quantidade de comunidades remanescentes de quilombos reconhecidas encontra-se no Nordeste (2.138), seguida da região Sudeste (527), Norte (366), Sul (191) e Centro-Oeste (164). A maioria não tem acesso às políticas públicas.

Embora com histórico de vitimização étnica e social, os quilombolas não têm sido comtemplados pelas políticas públicas de saúde mental. Além disso, poucos estudos investigaram suas condições de saúde e saúde mental. As investigações sobre a saúde mental das populações tradicionais brasileiras são muito escassas. Apesar do Estado brasileiro ter reconhecido os direitos quilombolas na Constituição de 1988, lhes conferindo o direito à posse de suas terras, Barroso; Melo; Guimarães (2014), concluem que "as áreas quilombolas são predominantemente rurais, com pouca infraestrutura e 
reduzido acesso aos serviços de saúde, o que caracteriza sua vulnerabilidade e gera questionamentos sobre a saúde física e mental dessa população."

Sendo assim, a literatura analisada aponta que a população quilombola vem sendo desconsiderada nas políticas públicas de saúde, apesar da promoção do direito à saúde ser se uma obrigação do Estado brasileiro desde a Constituição de 1988. Conforme se apurou, a negação desse direito a essa população está relacionada ao racismo institucional, que desconsidera a necessidade de políticas públicas com recorte racial e, consequentemente, políticas públicas voltadas à saúde mental da população quilombola.

\section{A (NÃO) INSERÇÃO DA PSICOLOGIA NO CONTEXTO DAS COMUNIDADES QUILOMBOLAS}

Especificamente sobre a atuação de psicólogos dentro das comunidades quilombolas de forma geral, Oliveira et al. (2017) apontam que com o surgimento da Reforma Psiquiátrica no Brasil, o modelo vigente de atenção à saúde mental, curativa e excludente, passou a ser rediscutido. Com isso, atribuindo-se outro sentido às práticas de base comunitária, tendo como eixo norteador das ações o coletivo, com foco na promoção da saúde, prevenção do adoecimento e a inclusão social, tendo em vista os sujeitos, a família e os grupos sociais.

De acordo com Rocha e Santos (2015), uma maior inserção da Psicologia no contexto das comunidades tradicionais ocorreu ligada à crescente aproximação da Psicologia com o debate acerca dos Direitos Humanos, em uma perspectiva ética e política, no que se refere à inserção em contextos de violação de direitos e às intervenções possíveis. Os autores também mencionam a inserção da Psicologia através da perspectiva social-comunitária, com um trabalho voltado à promoção da saúde, tratando os indivíduos enquanto sujeitos formados dentro de um contexto territorial marcado por diversos dramas e conflitos.

Para Rocha e Santos (2015), ao se trabalhar promoção de saúde nesse contexto, é possível pensar estratégias acessíveis ao sujeito, no que se refere ao processo saúdedoença-cuidado, visando a garantia da autonomia nas ações de cuidado a partir do acesso aos equipamentos públicos disponíveis no seu território. E todo esse processo inicialmente é intermediado pela Estratégia de Saúde da Família, a partir de ações 
orientadas pela Educação Popular em Saúde, sobre o amparo da Política Nacional de Promoção da Saúde. A partir da promoção de saúde se cria novas formas de geração de renda, e isso estimula a população na organização política para obtenção de apoio e promoção de saúde. O trabalho na promoção da saúde possibilita o fortalecimento da identidade ligada a aspectos materiais, históricos e culturais, contribuindo na melhoria das condições de vida e saúde mental da população.

As políticas públicas, como citado por Fernandes e Munhoz (2012), são vistas como estratégias que atuam diretamente na vida e produção do indivíduo. Sendo assim, o aspecto psicológico deve ser considerado e integrado através de ações que, por meio de políticas públicas, possibilitem a produção de práticas que atendam às necessidades das comunidades, levem em consideração sua subjetividade e não sigam uma forma rígida e autoritária.

Dentro dessa perspectiva, pensando em uma atuação nos contextos dessas comunidades tradicionais, podem ser elencadas algumas estratégias que possibilitem contribuições para o trabalho da Psicologia, algumas delas são: revisão sistemática dos conhecimentos produzidos em Psicologia no que tange ao trabalho comunitário e ao debate das relações raciais e das questões da terra; trabalho alicerçado nas proposições da Clínica Ampliada; resgate da historicidade da formação do povo; luta pela garantia dos Direitos Humanos através da articulação com instâncias governamentais nos níveis federal, estadual e municipal. (ROCHA; SANTOS, 2015).

Essas estratégias podem vir a contribuir com o necessário enfrentamento do racismo, pois segundo apontam Rocha e Santos (2015), tanto o racismo quanto seus derivados são causadores de sofrimento psíquico e injustiças sociais. Nesse contexto, a problematização da vulnerabilidade social dialogada com a temática do racismo institucional.

Ressaltando a necessidade de criação de políticas públicas especificas que direcionem a atuação do Estado para o fortalecimento da área da saúde, Rocha e Santos (2015), argumentam que a Psicologia deveria ser uma das áreas do conhecimento alicerce para se pensar e enfrentar o racismo contra o negro, já que o mesmo é uma modalidade de violência, de desigualdade política e, como tal, é ou pode ser promotor de persistente sofrimento psíquico vivido por e entre os negros. 
Sendo assim, de acordo com Fernandes e Santos (2019), o trabalho do psicólogo dentro das comunidades quilombolas deve identificar as demandas e as necessidades de saúde inseridas no cotidiano dessa população. Assim, conhecer o modo de vida presente nas comunidades quilombolas permite à psicologia intensificar o princípio da equidade no trabalho em saúde e efetivar em sua prática a luta pela garantia de direitos, sendo dado à Psicologia o objetivo de discutir a igualdade para que, assim, se busque direitos e recursos que ainda são negados às comunidades quilombolas.

Porém, segundo Barroso; Melo; Guimarães (2014), faltam publicações de artigos que tragam conhecimentos na área das Ciências Humanas sobre a saúde nas comunidades quilombolas, sendo que também se verifica uma reduzida participação de psicólogos no campo das relações étnico-raciais e das desigualdades relacionadas aos negros. Ademais, essa população vem sendo negligenciada nas políticas públicas de saúde.

O Conselho Federal de Psicologia de Brasília (2020) ressalta a importância da saúde mental da população negra e o quanto se faz necessário olhar para essa população, visto que as crises sociais, econômicas e políticas têm um impacto muito severo nas populações negras, promovendo ainda mais desigualdade, racismo estruturante e múltiplas formas de violência.

Nessa perspectiva, ressalta-se a importância do trabalho da (o) psicóloga (o) que, segundo o código de ética, deve promover a saúde e a qualidade de vida das pessoas e das coletividades, contribuindo para a eliminação de quaisquer formas de negligência, discriminação, violência e opressão, atuando com responsabilidade social, investigando crítica e historicamente a realidade política, econômica, social e cultural. (CONSELHO FEDERAL DE PSICOLOGIA, 2005).

Desse modo, foi constatado que a partir da Política Nacional de Assistência Social-PNAS, que tem sua base de criação e serviços estruturados no Sistema Único de Assistência Social - SUAS, foi possível proporcionar por meio dos Centros de Referência da Assistência Social - CRAS, a inserção de serviços que visam olhar para a saúde da população quilombola, que se encontra inserida em um contexto visto como vulnerável e de alto risco social. Dentro desses serviços encontra-se o trabalho da Psicologia. Porém, foi identificada uma escassez de estudos direcionados a essa atuação. Isso demonstra o quanto é nova a produção de estudos direcionados a essa temática, assim como a inserção da Psicologia dentro de um contexto marcado por diversas formas de vulnerabilidade e 
adoecimento mental. Apesar do aumento da inserção da Psicologia nas comunidades tradicionais nos últimos anos, existe uma lacuna na formação das (dos) psicólogas(os) no que se refere ao conhecimento dos problemas e demandas dessa população, o que acaba afetando bastante a contribuição que a Psicologia poderia dar no atendimento e resolução desses problemas e demandas.

\section{CONSIDERAÇÕES FINAIS}

Este estudo teve como objetivo realizar uma revisão de caráter descritivo de estudos que abordam a inserção da Psicologia dentro das comunidades quilombolas no Brasil, com ênfase no trabalho voltado às políticas públicas e à saúde mental.

Com base nos artigos analisados, conclui-se que os diferentes marcadores socias implicados na questão quilombola (população negra, pobre, rural, marginalizada, tradicional etc.), ao interseccionarem-se, excluem a população quilombola enquanto sujeitos de políticas públicas, tornando-a muitas vezes invisível perante o Estado, o que vem prejudicando o trabalho/atuação da Psicologia nessas comunidades. Observa-se a existência de políticas públicas voltadas à população rural, às comunidades tradicionais, à população negra, aos pobres etc., mas a população quilombola, ao englobar todos esses marcadores, não é contemplada em suas demandas específicas. As políticas públicas inseridas nas comunidades quilombolas, em sua maioria, limitam-se à questão de terra, deixando, assim, de atender outras várias demandas dessa população, sendo uma delas a criação de políticas voltadas à saúde, sobretudo à mental.

É importante considerar que a maioria dos trabalhos analisados ponderam a respeito de como seria a inserção da Psicologia dentro desse contexto, mas estudos que apresentem a atuação da(o) profissional de psicologia junto às comunidades quilombolas são escassos. Outra questão levantada pelos autores dos estudos analisados é a necessidade de capacitação dos profissionais de Psicologia no que se refere ao desenvolvimento de uma percepção e compreensão das especificidades culturais dessa população e da noção de compromisso social, que é uma das pautas historicamente defendidas pelo movimento de deselitização da Psicologia brasileira, mas cujo alcance ainda não foi capaz de abarcar as demandas de remanescentes quilombolas. 
ALMEIDA, Silvio Luiz de. Racismo Estrutural. 1. Ed. São Paulo: Editora Pólem Livros, 2019.

BARROSO, Sabrina Martins; MELO, Ana Paula Souto; GUIMARÃES, Mark Drew Crosland. Depressão em comunidades quilombolas no Brasil: triagem e fatores associados. Revista Panamericana de Salud Pública, v. 35, n.4, p. 256-263, fev. 2014. Disponível em: <https://www.scielosp.org/pdf/rpsp/2014.v35n4/256-263/pt>. Acesso em: 22 nov. 2020.

BATISTA, Eraldo Carlos; ROCHA, Katia Bones. Saúde mental em comunidades quilombolas do brasil: uma revisão sistemática da literatura. Interações (Campo Grande), [S.L.], p. 35-50, jan. 2020. Universidade Católica Dom Bosco. Disponível em:〈http://dx.doi.org/10.20435/inter.v21i1.2149>. Acesso em: 22 nov. 2020.

BRASIL. MINISTÉRIO DA SAÚDE. Secretaria de Gestão Estratégica e Participativa. Departamento de Apoio à Gestão Participativa e ao Controle Social. Óbitos por suicídio entre adolescentes e jovens negros 2012 a 2016. Universidade de Brasília, Observatório de Saúde de Populações em Vulnerabilidade. Brasília: Ministério da Saúde, 2018. Disponível em: <https://bvsms.saude.gov.br/bvs/publicacoes/obitos_suicidio_adolescentes_negros_2012_2016. pdf?fbclid=IwAR1JvKQIuNZNIT6s_XKYEm6OiAUWfWH1toENITr1xUB1TjV_wlWCeA1i $\underline{\mathrm{BIM}}>$. Acesso em: 05 out. 2020.

CARDOSO, Lourenço; GOMES, Lilian. Movimento negro e movimento quilombola: para uma teoria da tradução. Revista da Associação Brasileira de Pesquisadores/as Negros/as (ABPN), [S.1.], v. 10, n. 26, p. 153-171, out. 2018. ISSN 2177-2770. Disponível em: <https://abpnrevista.org.br/index.php/site/article/view/644>. Acesso em: 16 fev. 2021.

CONSELHO FEDERAL DE PSICOLOGIA. Código de ética profissional do psicólogo. Brasília, 2005. Disponível em: <https://site.cfp.org.br/wp-content/uploads/2012/07/codigo-de-eticapsicologia.pdf>. Acesso em: 12 set. 2020.

CONSELHO FEDERAL DE PSICOLOGIA. Relações raciais: referências técnicas para atuação de psicólogas/os. Brasília: CFP, 2017. Disponível em: <https://site.cfp.org.br/wpcontent/uploads/2017/09/relacoes_raciais_baixa.pdf >. Acesso em: 11 set. 2020.

CONSELHO FEDERAL DE PSICOLOGIA. Saúde mental da população negra importa. Brasília: CFP, 2020. Disponível em: 〈https://site.cfp.org.br/saude-mental-da-populacao-negra-importa/〉. Acesso em: 17 nov. 2020.

COSTA, Eliane Silvia; SCARCELLI, Ianni Regia. psicologia, política pública para a população quilombola e racismo. Psicologia USP, [S.L.], v. 27, n. 2, p. 357-366, abr. 2016. Disponível em: <http://dx.doi.org/10.1590/0103-656420130051> .Acesso em: 16 jan. 2020.

CUNHA, Felipe Gibson; COSTA, Sebastião Guilherme Albano da. Identidades quilombolas: políticas, dispositivos e etnogêneses. Latinoamérica. Revista de Estudios Latinoamericanos, [S.L.], n. 64, p. 153-184, maio. 2017. Universidad Nacional Autonoma de Mexico. Disponível em: <http://dx.doi.org/10.22201/cialc.24486914e.2017.64.56864 >. Acesso em: 15 out. 2020.

DE-LA-TORRE-UGARTE-GUANILO, Mônica Cecilia; TAKAHASHI, Renata Ferreira; BERTOLOZZI, Maria Rita. Revisão sistemática: noções gerais. Revista da Escola de Enfermagem da Usp, [S.L.], v. 45, n. 5, p. 1260-1266, out. 2011. Disponível em:< http://dx.doi.org/10.1590/s0080-62342011000500033>. Acesso em: 18 maio. 2020. 
FELICISSIMO, Flaviane Bevilaqua; FERREIRA, Gabriela Correia Lubano; SOARES; Rhaisa Gontijo; SILVEIRA, Pollyanna Santos da; RONZANI, Telmo Mota. Estigma internalizado e autoestima: uma revisão sistemática da literatura. Psicologia: Teoria e pratica, São Paulo, v. 15, n. 1, p. 116-129, abr. 2013. Disponível em $<$ http://pepsic.bvsalud.org/scielo.php?script=sci_arttext\&pid=S1516-

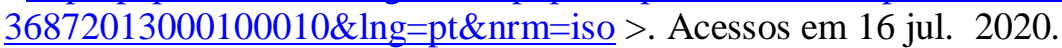

FERNANDES, Saulo Luders; MUNHOZ, Julia Minossi. Atuações das políticas quilombolas e suas repercussões nos processos de subjetivação de comunidades negras rurais. In: V CIPSICongresso Internacional de Psicologia, 2012. Anais. Maringá: Universidade Estadual de Maringá, 2012. Disponível em: <http://eventos.uem.br/index.php/cipsi/2012/paper/view/427/251>. Acesso em: 16 nov. 2020.

FERNANDES, Saulo Luders; SANTOS, Alessandro de Oliveira dos. Itinerários terapêuticos e formas de cuidado em um quilombo do agreste alagoano. Psicologia: Ciência e Profissão, [S.L.], v. 39, p. 38-52, maio. 2019. Disponível em: 〈http://dx.doi.org/10.1590/1982-3703003176272〉. Acesso em: 6 dez. 2020.

FERREIRA, Ricardo Frankllin; CAMARGO, Amilton Carlos. As relações cotidianas e a construção da identidade negra. Psicologia: Ciência e Profissão, [S.L.], v. 31, n. 2, p. 374-389, 2011. Disponível em: 〈http://dx.doi.org/10.1590/s1414-98932011000200013〉. Acesso em: 25 set. 2020.

FREITAS, Daniel Antunes; CABALLERO, Antonio Diaz; MARQUES, Amaro Sérgio; HERNÁNDEZ, Clara Inés Vergara; ANTUNES, Stéffany Lara Nunes Oliveira. Saúde e comunidades quilombolas: uma revisão da literatura. Revista Cefac, [S.L.], v. 13, n. 5, p. 937943, 20 maio 2011. Disponível em: 〈http://dx.doi.org/10.1590/s1516-18462011005000033〉. Acesso em: 25 set. 2020.

FURTADO, Marcella Brasil; PEDROZA, Regina Lúcia Sucupira; ALVES, Cândida Beatriz. Cultura, identidade e subjetividade quilombola: uma leitura a partir da psicologia cultural. Psicologia \& Sociedade, [S.L.], v. 26, n. 1, p. 106-115, abr. 2014. Disponível em: <http://dx.doi.org/10.1590/s0102-71822014000100012>. Acesso em: 22 set. 2020.

GOMES, Daiane de Oliveiva; BRANDÃO, Wanessa Nhayara Maria Pereira; MADEIRA, Maria Zelma de Araújo. Justiça racial e direitos humanos dos povos e comunidades tradicionais. Revista Katálysis, [S.L.], v. 23, n. 2, p. 317-326, ago. 2020. Disponível em: <http://dx.doi.org/10.1590/1982-02592020v23n2p317> . Acesso em: 15 out. 2020.

MÄDER, Bruno Jardini (org.). Caderno de psicologia e relações étnico-raciais: diálogos sobre o sofrimento psíquico causado pelo racismo. Curitiba: CRP-PR, 2016. Disponível em: $<$ https://crppr.org.br/wp-content/uploads/2019/05/AF CRP CadernoEtnico_Social_pdf.pdf >. Acesso em: 20 abr. 2021.

MARQUESE, Rafael de Bivar. A dinâmica da escravidão no brasil: resistência, tráfico negreiro e alforrias, séculos xvii a xix. Novos Estudos - Cebrap, [S.L.], n. 74, p. 107-123, mar. 2006.

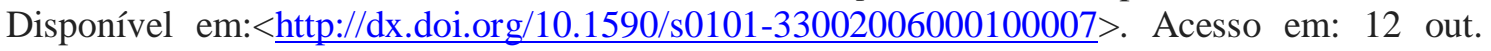
2020.

MOURA, Clóvis. Quilombos: Resistência ao Escravismo. 3. ed. São Paulo: Atica S.A, 1993.

NASCIMENTO, Abdias. O quilombismo: Documentos de uma Militância Pan-africana. 3. ed. São Paulo: Editora Perspectiva, 2019. 
OLIVEIRA, Sanni Moraes De; MENEZES JUNIOR, Jonas Oliveira; SILVA JUNIOR, Sergio Vital da; DIAS, Maria Djair; FERNANDES, Maria das Graças Melo; FERREIRA FILHA, Maria de Oliveira. Rodas de terapia comunitária: construindo espaços terapêuticos para idosos em comunidades quilombolas. Revista de Enfermagem da Ufsm, [S.L.], v. 7, n. 4, p. 712, nov. 2017. Universidad Federal de Santa Maria. Disponível em: $\langle$ http://dx.doi.org/10.5902/2179769220299 >. Acesso em: 12 out. 2020.

ROCHA, Renan Vieira de Santana; SANTOS, Lumena de Aleluia. Psicologia e promoção da saúde: Fortalecimento dos direitos humanos em comunidades tradicionais. Revista Brasileira de Psicologia, [S.L.], v. 2, n. esp, p. 61-72, 2015. Disponível em: <file:///C:/Users/gyale/Downloads/elibrary.tips_psicologia-e-promoao-da-saude-fortalecimentodos-direitos-humanos-em-comunidades-tradicionais\%20(4).pdf>. Acesso em: 27 nov. 2020.

ROSO, Adriane; GASS, Rosineia L.; ORSATO, Daniela.; ALVES, Thiago.; MORAES, Mauricio Minorias étnicas e representações sociais: notas sobre a entrada do psicólogo social em uma comunidade Quilombola. Psico, Porto Alegre, PUCRS, v. 42, n. 3, p. 346-353, jul/set. 2011. Disponível

em: $<$ https://revistaseletronicas.pucrs.br/ojs/index.php/revistapsico/article/view/9914>. Acesso em: 16 jan. 2021.

SAMPAIO, Rf; Mancini, Mc. Estudos de revisão sistemática: um guia para síntese criteriosa da evidência científica. Revista Brasileira de Fisioterapia, [S.L.], v. 11, n. 1, p. 83-89, fev. 2007. Disponível em: 〈http://dx.doi.org/10.1590/s1413-35552007000100013〉. Acesso em: 22 jul. 2020.

SCHWARCZ, Lilia Moritz; STARLING, Heloisa Murgel. BRASIL: uma biografia. Ed. 1. São Paulo: Companhia das Letras, 2015.

SILVA, André Ricardo Fonseca da. Políticas públicas para comunidades quilombolas: uma luta em construção. Revista de Ciências Sociais - Política \& Trabalho, [S.L.], v. 1, n. 48, p. 115-128, 12 jul. 2018. Disponível em: 〈http://dx.doi.org/10.22478/ufpb.1517-5901.2018v1n48.27650>. Acesso em: 21 nov. 2020.

SILVA, Antonino Alves; CHAVES, Silvane Lopes. Problematização sobre vulnerabilidade social e racismo institucional nas ações desenvolvidas por cras quilombola. Revista Brasileira de Psicologia, v. 2, n. esp, p. 100-108, 2015. Disponivel em: $<$ https://scholar.google.com.br/scholar?hl=pt-

BR\&as_sdt=0\%2C5\&q=SILVA\%2C+Antonino+Alves\%3B+CHAVES\%2C+Silvane+Lopes.+ Problematiza\%C3\%A7\%C3\%A3o+sobre+vulnerabilidade+social+e+racismo+institucional+nas $+\mathrm{a} \% \mathrm{C} 3 \% \mathrm{~A} 7 \% \mathrm{C} 3 \% \mathrm{~B} 5 \mathrm{es}+$ desenvolvidas+por+CRAS+quilombola.+\&btnG $>$. Acesso em: 17 out. 2020.

SILVA, Simone Rezende. Quilombos no brasil: a memória como forma de reinvenção da identidade e territorialidade negra. In: COLÓQUIO INTERNACIONAL DE GEOCRÍTICA, 12., Colômbia, maio. 2012. Disponível em: <http://www.ub.edu/geocrit/coloquio2012/actas/08-SRezende.pdf>. Acesso em: 22 out. 2020.

TEIXEIRA, Tadeu Gomes; SAMPAIO, Camila Alves Machado. Análise orçamentária do programa brasil quilombola no brasil e no maranhão: o ocaso de uma política pública. Revista de Administração Pública, [S.L.], v. 53, n. 2, p. 461-480, abr. 2019. Disponível em: 〈http://dx.doi.org/10.1590/0034-761220170323〉. Acesso em: 18 nov. 2020. 
VIEIRA, Ana Beatriz Duarte; MONTEIRO, Pedro Sadi. Comunidade quilombola: análise do problema persistente do acesso à saúde, sob o enfoque da bioética de intervenção. Saúde em Debate, Rio de Janeiro, v. 37, n. 99, p. 610-618, out. 2013. Disponível em: <https://www.scielo.br/j/sdeb/a/GwYSxxVb5DCDkyrXhSxW4JG/?format=pdf\&lang=pt >. Acesso em: 15 out. 2020.

Recebido em: 13/09/2021

Aceito em: 16/11/2021 